\title{
Does the Autologue Fibrin Glue Enhance the Regeneration of In- trabony Defects in Aggressive Periodontitis?
}

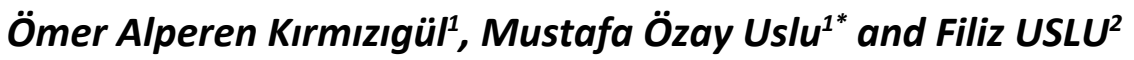 \\ ${ }^{1}$ Department of Periodontology, Inonu University, Turkey \\ ${ }^{2}$ Department of Orthodontics, Inonu University, Turkey
}

*Corresponding author: Dr. Mustafa Özay Uslu, Assistant Professor, MD, Ph.D, Department of Periodontology, Inonu University, 44280, Malatya, Turkey, Tel: +90422-3411100-6254, Fax: +90422-3411107

\begin{abstract}
Introduction: Aggressive periodontitis is a rapid periodontal destruction that develops in early and affects systemically healthy individuals. As in all periodontal diseases, the main purpose of aggressive periodontitis treatment is to enable the patient to maintain his function and aesthetics with her natural teeth in optimal health conditions. The most appropriate treatment for this purpose is periodontal regeneration methods. In this case report, regenerative treatment of intrabony defects with xenograft and autologue fibrin glue was presented.
\end{abstract}

Methods: A systemically healthy with a history of orthodontic treatment, 23-years-old female patient was referred to our clinic with complaints of infection and mobility in teeth. Localized aggressive periodontitis was diagnosed and intrabony defects were detected as a result of clinical and radiographic examinations. Multiple intrabony defects was detected. Intrabony defects in the mandibula and maxilla were planned to treat with xenograft and barrier membrane after initial periodontal therapy. The usage of xenograft, otogen fibrin glue and barrier membrane were planned to treat the intrabony defect of upper left central incisor tooth. The patient was prescribed antibiotics, anti-inflammatory drug and chlorhexidine gluconate after the operation and sutures were taken at postoperative $10^{\text {th }}$ day. Clinical parameters such as average pocket depth, clinical attachment level, gingival recession and tooth mobility were recorded. Radiographs were taken at baseline, postoperative $3^{\text {th }}$ and $6^{\text {th }}$ month.

Results: Postoperative healing of patient was uneventful. Pocket depth was reduced, and satisfactory bone gain was achieved after treatment.

Conclusions: As seen in this case, clinically successful results can be achieved by using bone grafts with autologue fibrin glue in the treatment of intrabony defects in aggressive periodontitis.

\author{
Keywords \\ Aggressive periodontitis, Autologue fibrin glue, Regeneration
}

\section{Introduction}

Aggressive periodontitis is considered a complex periodontal disease affecting the dentition with pronounced and rapid destruction of the periodontium and may result in loss of teeth and/or formation of advanced periodontal defects [1]. Angular bone defects seen radiographically in permanent first molar and central incisor teeth are the most prominent feature of this periodontal disease [2]. The localized form affects specifically first molar and central incisor teeth by causing interproximal attachment loss. In addition to that, up to two teeth other than these may be affected. The generalized form of aggressive periodontitis affects three or more teeth except first molar and central incisor teeth [3]. In this disease; Circumferential bone defects affecting two-thirds of the roots and tooth-supporting tissues can be seen in a few years due to rapid bone destruction. As a result of disease progression, severe mobility and intrabony defects can be seen in the related areas. Also, pus discharge can be observed [4]. Lesions are often symmetric. It's more common in women than in men. Clinically, gingival tissues are normal and bacterial plaque accumulation is low, and attachment loss is 4-5 times the severity seen in adults. It is thought that the disease is genetic, autosomal recessive or $\mathrm{x}$-chromosomal dominant a transition $[1,3]$.

Citation: Kırmızıgül OA, Uslu MO, Filiz USLU (2018) Does the Autologue Fibrin Glue Enhance the Regeneration of Intrabony Defects in Aggressive Periodontitis?. Int J Oral Dent Health 4:060. doi. org/10.23937/2469-5734/1510060

Accepted: September 11, 2018: Published: September 13, 2018

Copyright: (C) 2018 Kırmızıgül OA, et al. This is an open-access article distributed under the terms of the Creative Commons Attribution License, which permits unrestricted use, distribution, and reproduction in any medium, provided the original author and source are credited. 


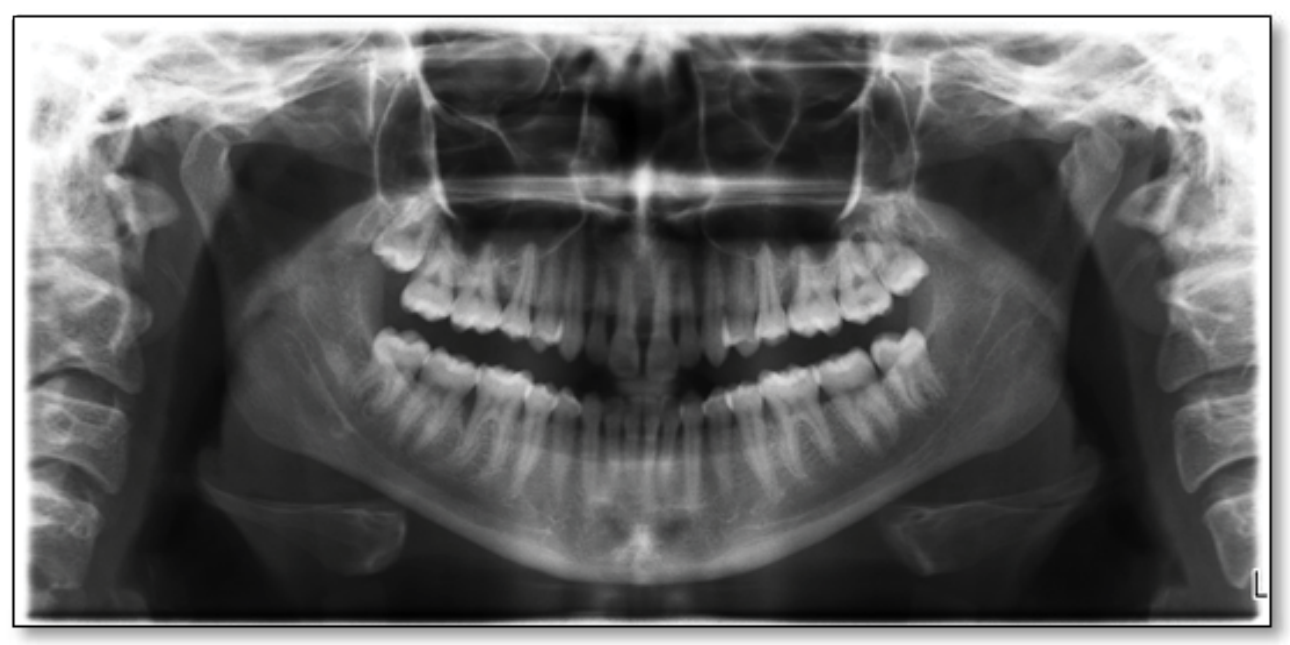

Figure 1: Pre-orthodontic radiography.

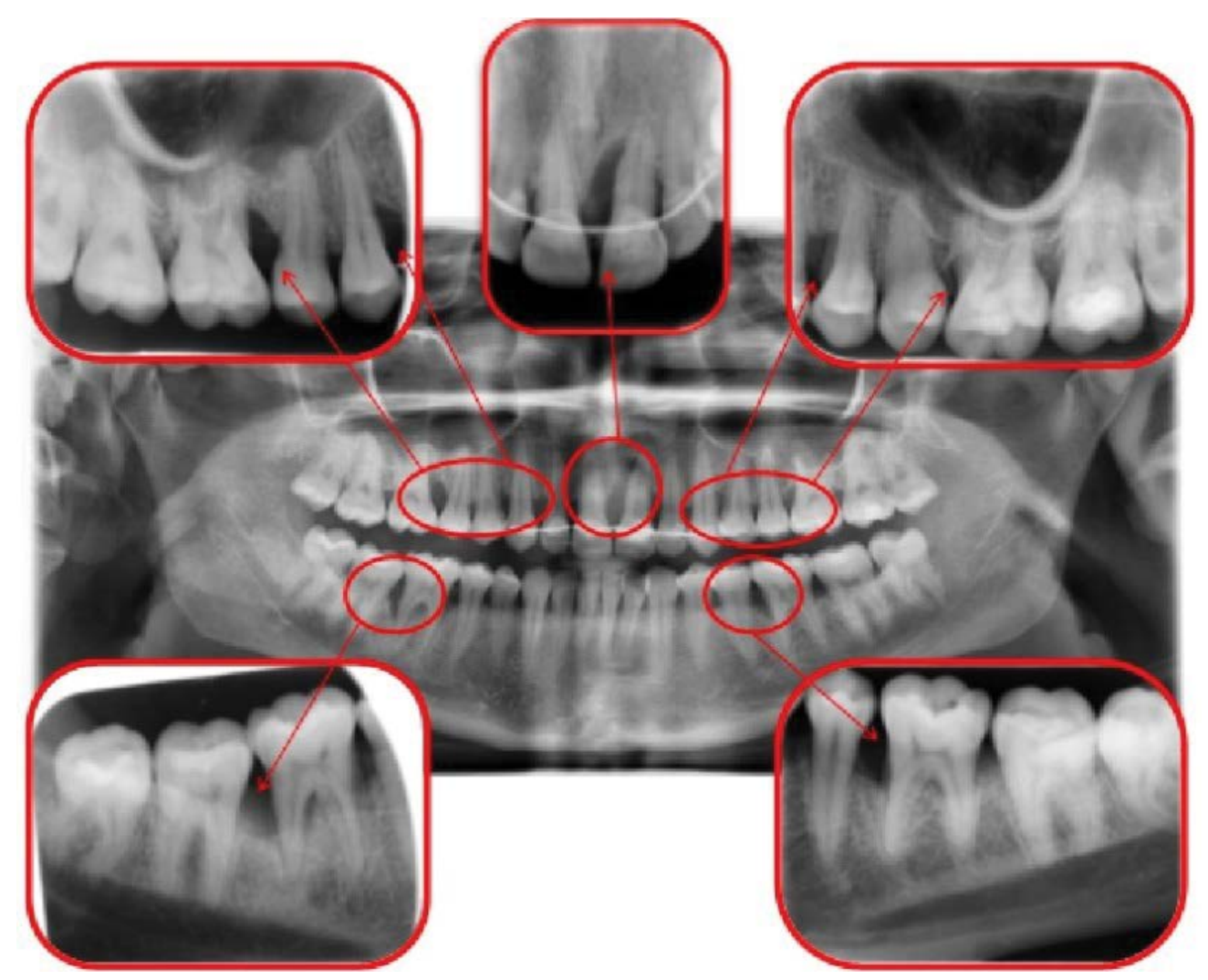

Figure 2: Post-orthodontic radiography.

Aggressive periodontitis has no universal treatment protocol [5]. In this case report, regenerative therapy of intrabony defects with autologue fibrin glue and xenograft combination was presented.

\section{Case Description}

A systemically healthy and 23-years-old female patient with a history of orthodontic treatment, was referred to our clinic with complaints of infection and mobility of the teeth. Localized aggressive periodontitis was diagnosed and intrabony defects were detected as a result of clinical and radiographic examinations (Figure 1 and Figure 2). Initial examination revealed good oral hygiene status, but deep periodontal pockets rang- ing from $6 \mathrm{~mm}$ to $12 \mathrm{~mm}$. Multiple intrabony defects was detected. Periodontal charting details before and after the initial periodontal therapy were given in (Figure 3 and Figure 4). Full mouth intraoral periapical radiographs and panoramic radiographies were obtained. Advanced vertical bony defects were determined in relation to upper right first premolar and first molar teeth, upper left central incisor and first premolar and first molar teeth, lower left and right first molar teeth at panoramic radiographies. The treatment plan consisted of full mouth scaling and root planning along with systemic administration of amoxicillin ( $625 \mathrm{mg} \times 3$ times) + metronidazole (500 $\mathrm{mg} \times 3$ times) during a total period of 7 days. Patient was recalled 6 weeks after initial 

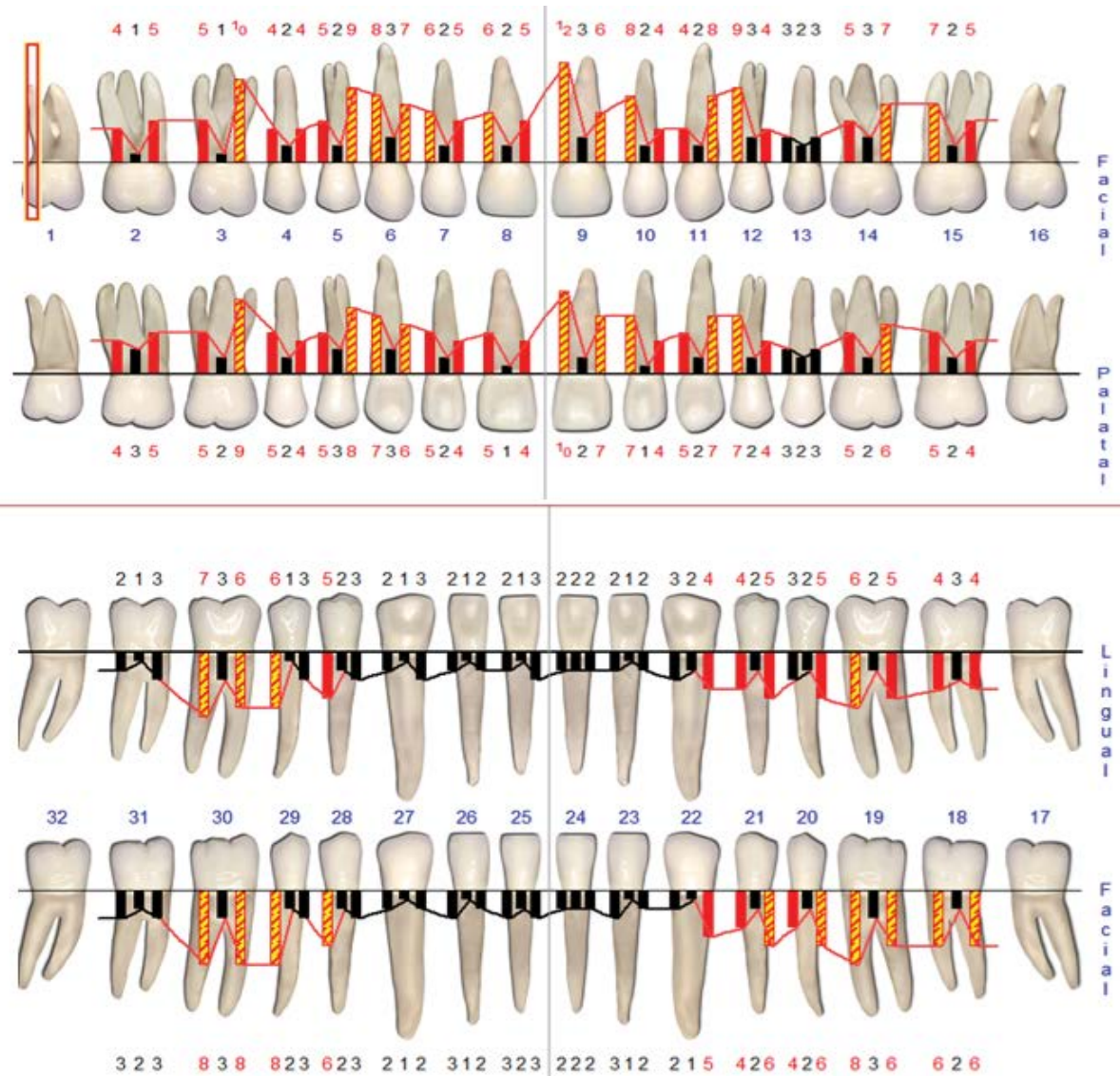

Figure 3: Periodontal charting at baseline.

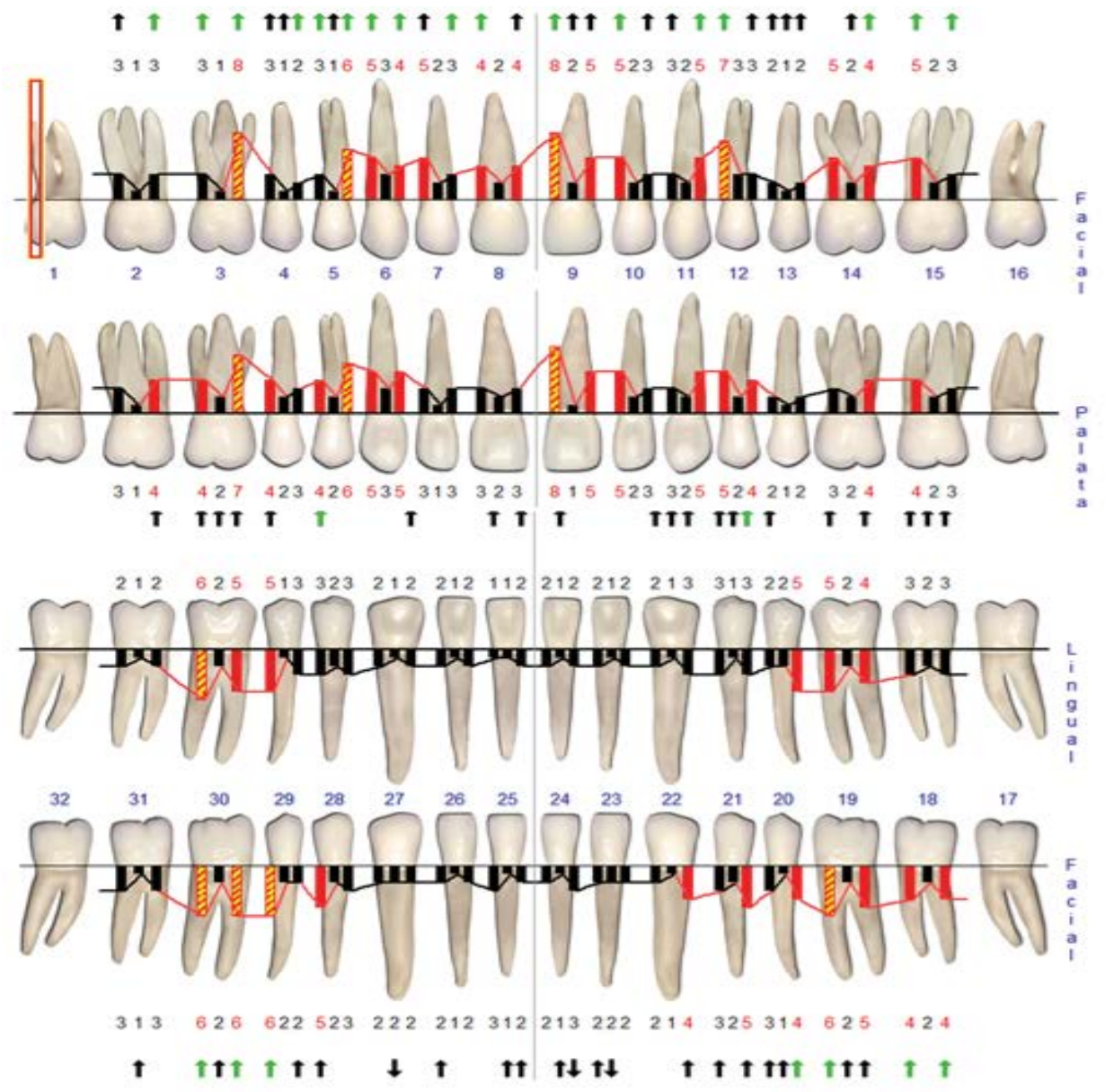

Figure 4: Periodontal charting after initial periodontal therapy. 


\section{Treatment Process}

\section{Initial Periodontal Therapy}

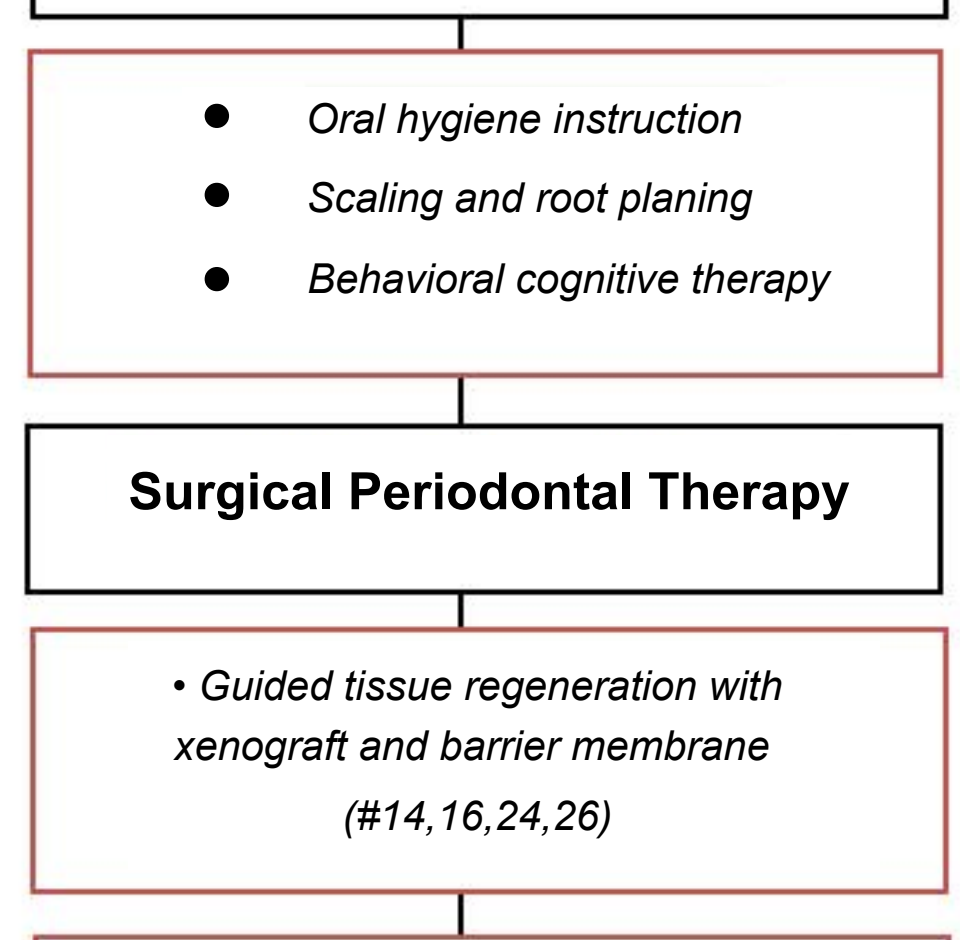

- Guided tissue regeneration with xenograft and barrier membrane (\#34,36,45,46)

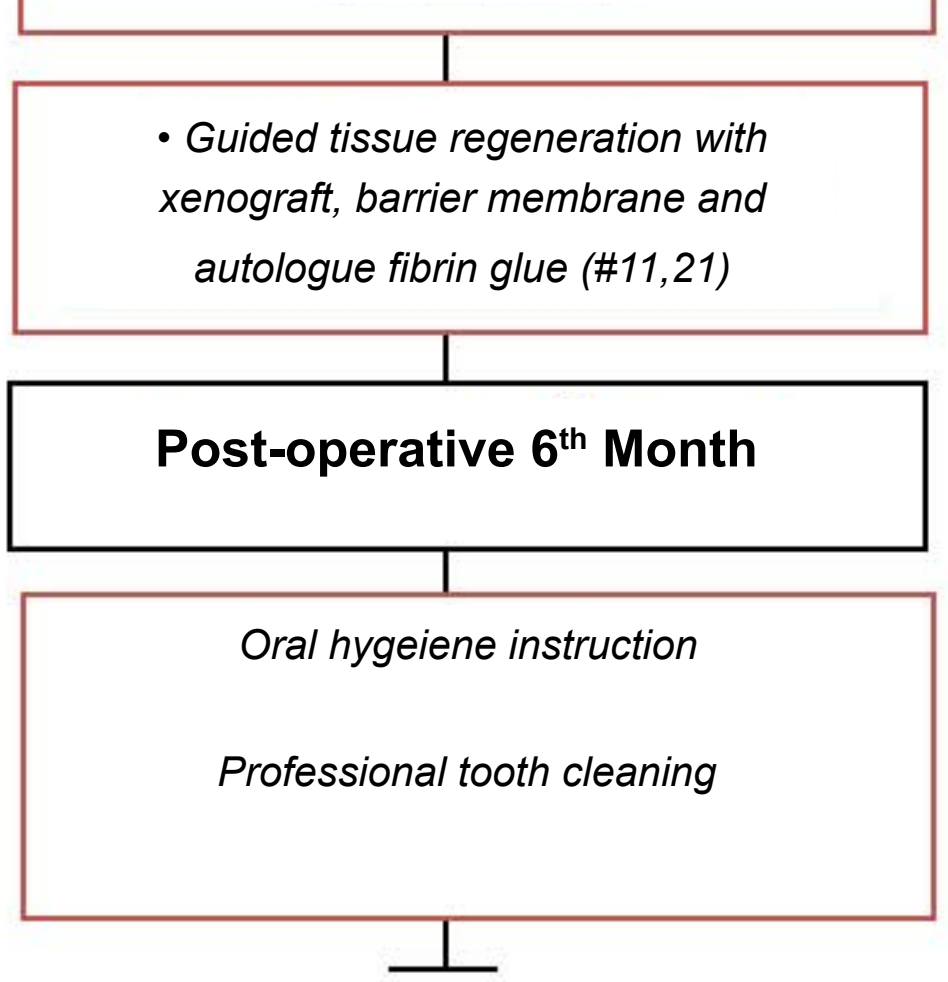

Figure 5: Treatment Process. 

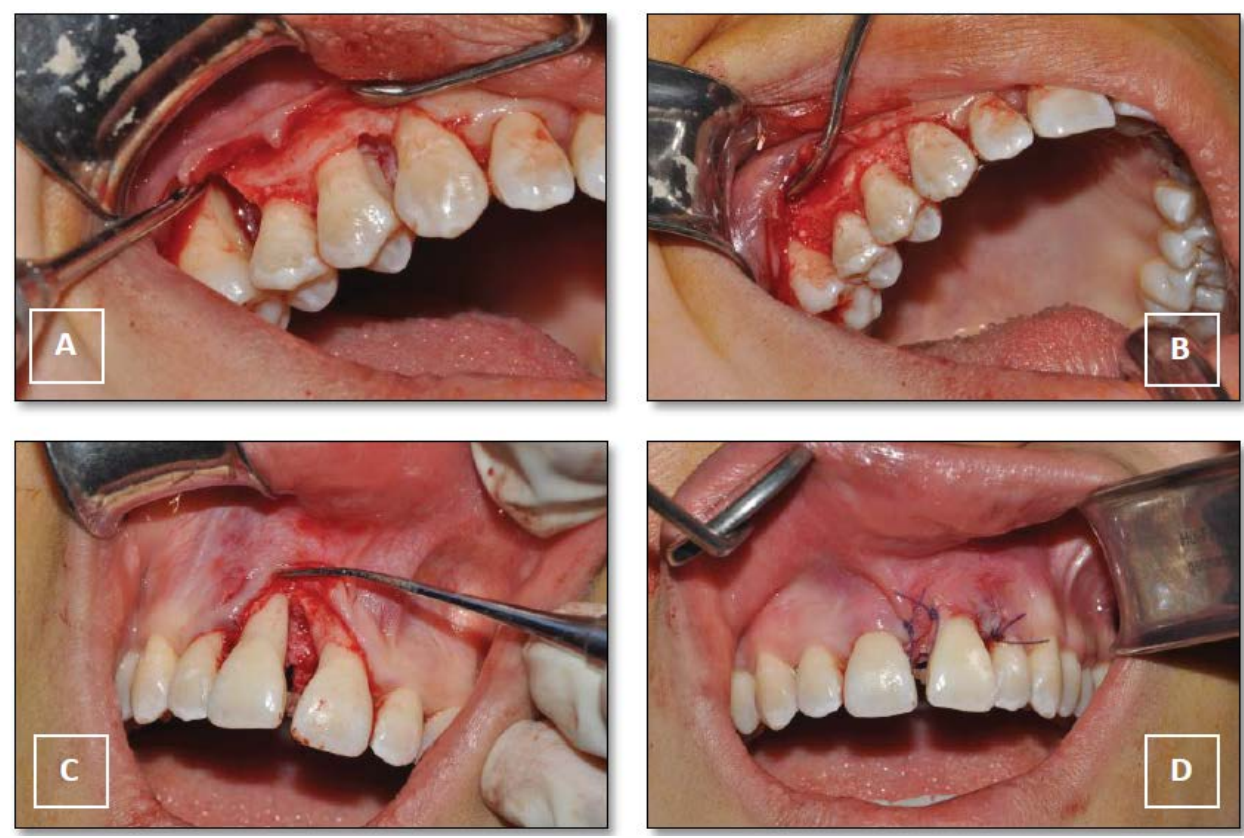

Figure 6: A) Intrabony defects at maxillary right side; B) Regenerative therapy with using membrane and xenografts; C) Deep intrabony defect at aesthetic region; D) Regenerative therapy with AFG \& xenograft-membrane combination.

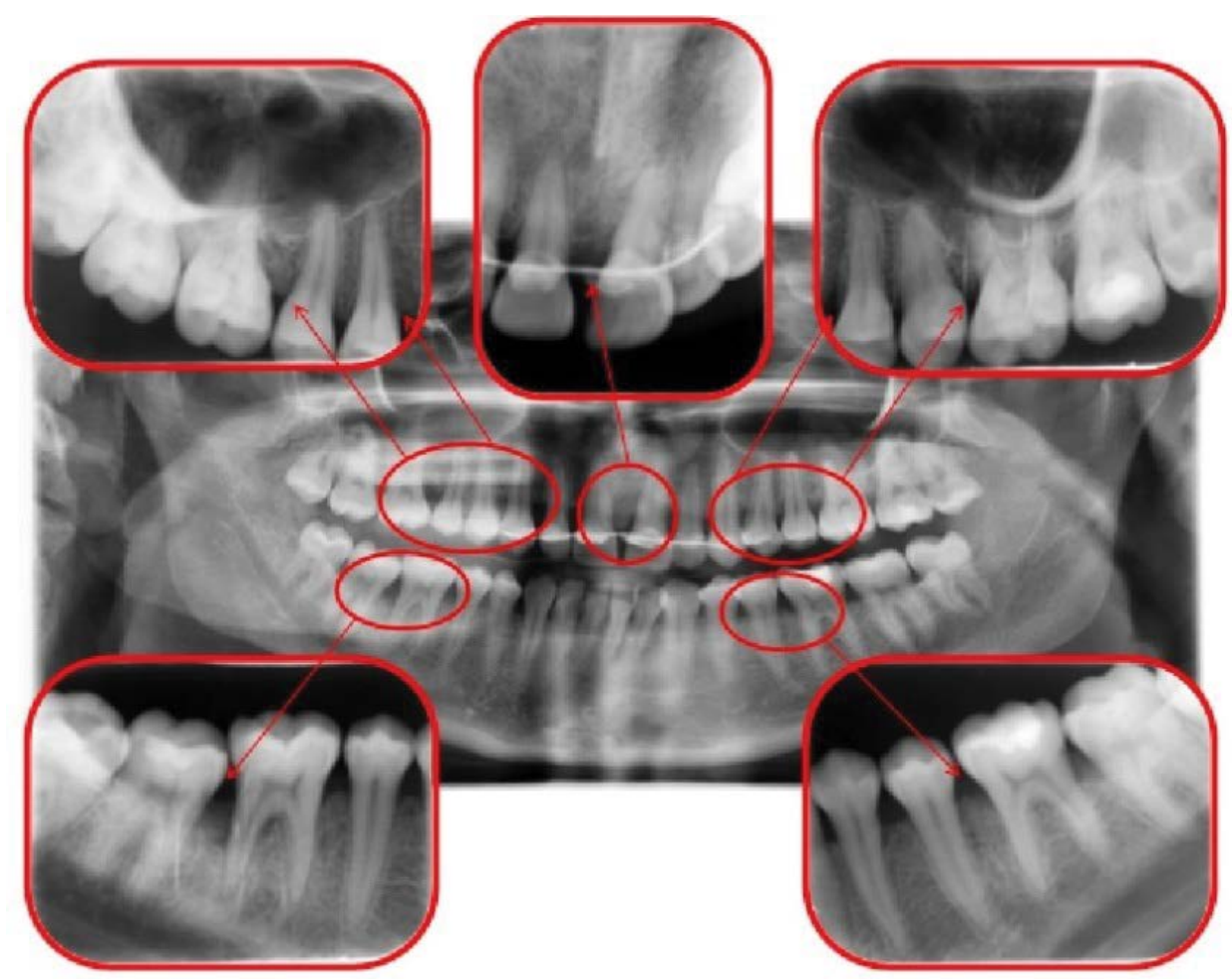

Figure 7: Post-treatment panoramic radiography.

periodontal therapy. The treatment process is shown on the Figure 5. Surgical intervention was deemed necessary. Intrabony defects in the mandibula and maxilla were planned to treat with xenograft (Cerabone 0.5$1 \mathrm{~mm}$ particle size, Botiss Dental GmbH, Germany) and barrier membrane (OsteoBiol Evolution, Tecnoss, Italy) after initial periodontal therapy. Unlike other regions, the usage of xenograft, otogen fibrin glue and barrier membrane were planned to treat the intrabony defect of upper left central incisor tooth (Figure 6). The patient was prescribed antibiotics, anti-inflammatory drug and chlorhexidine gluconate after the operation and sutures were taken at postoperative $10^{\text {th }}$ day. Radiographs were taken at baseline, postoperative $3^{\text {th }}$ and $6^{\text {th }}$ month. Radiograph obtained 6 months after the therapy was displayed approximately $85-90 \%$ bone gain of the defect and continuity of lamina dura (Figure 7). Clinical parameters such as average pocket depth, clinical attachment level, gingival recession and tooth mobility were recorded (Figure 8). Postoperative healing was satisfactory 


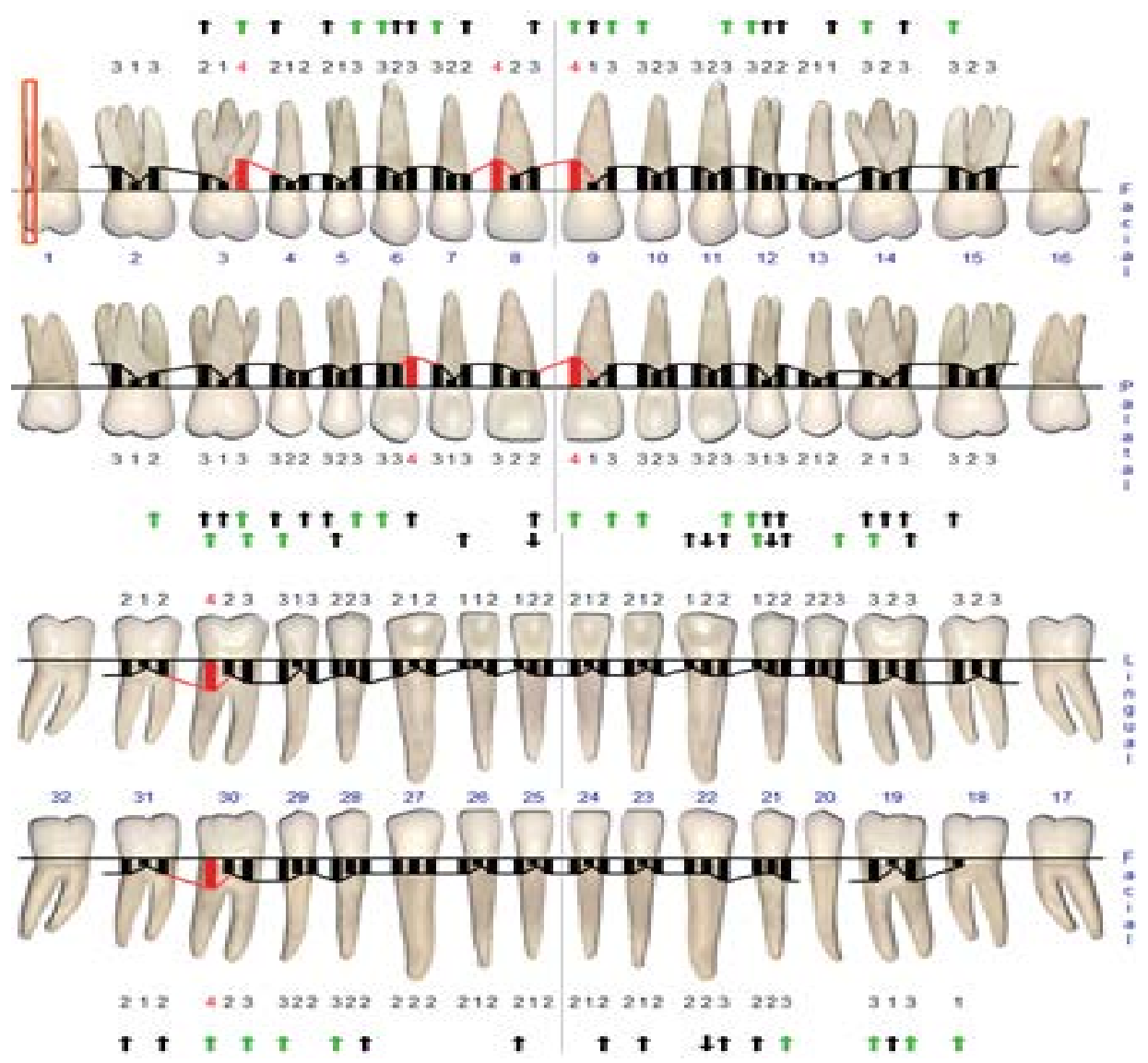

Figure 8: Periodontal charting after surgical periodontal therapy.

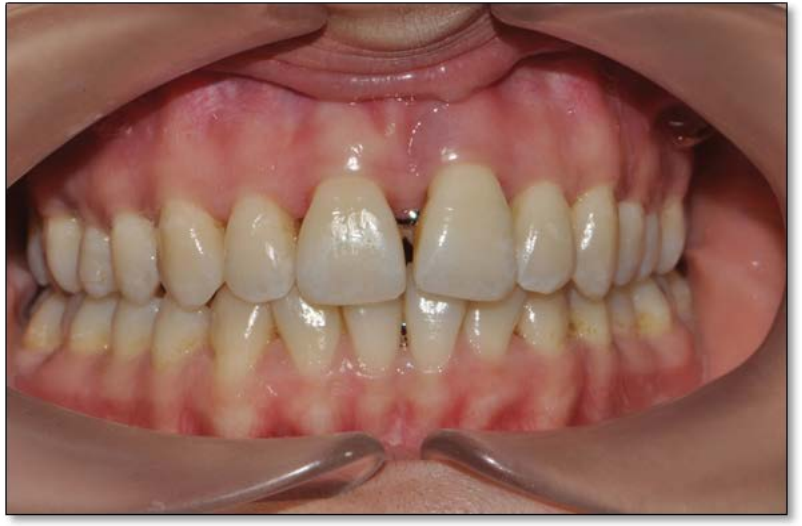

Figure 9: Post-treatment view of intraoral tissues.

with normal contours of periodontal tissues (Figure 9).

\section{Discussion}

Aggressive periodontitis affects young and systemically healthy individuals by causing rapid periodontal destruction $[6,7]$. As in all periodontal diseases, the main purpose of aggressive periodontitis treatment is to enable the patient to maintain function and aesthetics with the natural teeth in optimal health conditions. The most appropriate treatment for this purpose is periodontal regeneration methods.

The standard treatment protocol recommended for periodontal health rehabilitation and continuity in aggressive periodontitis patients; Mechanical treatment (scaling and root planning and/or periodontal surgery), mechanical treatment combined with antimicrobial therapy and frequent interval supportive periodontal treatment [8]. The relative efficacy on aggressive periodontitis is still unclear when non-surgical periodontal therapy is compared to chronic periodontitis [9]. There is limited opportunity to eradicate periodontopathogens in deep pockets with non-surgical periodontal therapy [10]. The healing process of non-surgical treatment results in persistent bleeding areas regurgitation, disease recurrence and long junctional epithelium [11]. However, periodontal pathogens can remain in the mouth even after tooth extraction [12]. Studies have shown that teeth with $50 \%$ bone loss have a suspicious prognosis to maintain their health and are ultimately "hopeless". It was reported that advanced bone defects, deep pockets and dental mobility seen in aggressive periodontitis, increase the risk of tooth loss $[13,14]$. For this reason, regenerative periodontal treatment of advanced periodontal defects seems promising to improve prognosis and extend the life span of teeth [15]. Ideal periodontal treatment aims at regeneration and reconstruction of lost periodontal tissue [16].

Thrombocyte concentrations have been used as often as every day as potential products of regenerative therapies. High interest in platelet concentrations has set the stage for the discovery of new products that enhance regeneration capacity. In view of the Platelet Rich Plasma, Plasma Rich in Growth Factors, Platelet-Rich 
Fibrin (PRF) types (Advanced-PRF, Titanium-prepared PRF, Injectable PRF) and Concentrated Growth Factor, each product was discovered in order to eliminate the deficiencies of the previous concentrate and to obtain a more advanced form. In 2010, Sohn developed an injectable platelet concentration 'Autologous Fibrin Glue' (AFG) by centrifuging venous blood in a special centrifuge and developed the concept of 'Sticky Bone', which allowed it to remain stable in graft defects by mixing it with bone grafts [17]. From the literature view, this platelet concentrate did not use for reducing pockets in periodontal diseases. In this case report the possible effects of AFG on periodontal tissues were investigated and satisfactory clinical results were achieved.

\section{Conclusions}

As seen in this case report, clinically satisfactory results can be achieved by using autologue fibrin glue with bone grafts in the treatment of intrabony defects of aggressive periodontitis.

\section{Acknowledgements}

No potential conflict of interest relevant to this case report was reported.

\section{References}

1. Armitage GC (1999) Development of a classification system for periodontal diseases and conditions. Ann Periodontol 4: 1-6.

2. Baer PN (1971) The case for periodontosis as a clinical entity. J Periodontol 42: 516-520.

3. Graetz C, Sälzer S, Plaumann A, Schlattmann P, Kahl M, et al. (1971) Tooth loss in generalized aggressive periodontitis: Prognostic factors after 17 years of supportive periodontal treatment. J Clin Periodontol 44: 612-619.

4. Giargia M, Lindhe J (1997) Tooth mobility and periodontal disease. J Clin Periodontol 24: 785-795.
5. Buchmann R, Nunn ME, Van Dyke TE, Lange DE (2002) Aggressive periodontitis: 5-year follow-up of treatment. J Periodontol 73: 675-683.

6. Albandar JM (2014) Aggressive periodontitis: Case definition and diagnostic criteria. Periodontol 2000 65: 13-26.

7. Chahboun H, Arnau MM, Herrera D, Sanz M, Ennibi OK (2015) Bacterial profile of aggressive periodontitis in Morocco: A cross-sectional study. BMC Oral Health 15: 25.

8. (2000) Parameter on aggressive periodontitis. American academy of periodontology. J Periodontol 71: 867-869.

9. Teughels W, Dhondt R, Dekeyser C, Quirynen M (2014) Treatment of aggressive periodontitis. Periodontol 2000 65: 107-133.

10. Wang HL, Greenwell H (2001) Surgical periodontal therapy. Periodontol 2000 25: 89-99.

11. Matuliene G, Pjetursson BE, Salvi GE, Schmidlin K, Brägger $U$, et al. (2008) Influence of residual pockets on progression of periodontitis and tooth loss: Results after 11 years of maintenance. J Clin Periodontol 35: 685-695.

12. Quirynen M, Van Assche N (2011) Microbial changes after full-mouth tooth extraction, followed by 2-stage implant placement. J Clin Periodontol 38: 581-589.

13. McGuire MK (1991) Prognosis versus actual outcome: A long-term survey of 100 treated periodontal patients under maintenance care. J Periodontol 62: 51-58.

14. McGuire MK, Nunn ME (1996) Prognosis versus actual outcome. III. The effectiveness of clinical parameters in accurately predicting tooth survival. J Periodontol 67: 666-674.

15. Murakami S, Bartold M, Meyle J, Agarwal R, Anagnostou F, et al. (2015) Group C. Consensus paper. Periodontal regeneration--fact or fiction? J Int Acad Periodontol 17: 54-56.

16. Wang HL, Greenwell H, Fiorellini J, Giannobile W, Offenbacher S, et al. (2005) Periodontal regeneration. J Periodontol 76: 1601-1622.

17. Sohn DS (2010) Lecture titled with sinus and ridge augmentation with CGF and AFG. 